Article

\title{
Possible Power Quality Ancillary Services in Low-Voltage Grids Provided by the Three-Phase Damping Control Strategy
}

\author{
Dimitar V. Bozalakov ${ }^{1, *,+(\mathbb{D})}$, Joannes Laveyne ${ }^{1,+(\mathbb{D})}$, Mohannad J. Mnati ${ }^{2,+} \mathbb{D}$, \\ Jan Van de Vyver ${ }^{3,+}$ and Lieven Vandevelde ${ }^{1,4, *,+}$ id \\ 1 Electrical Energy Laboratory (EELAB), Department of Electromechanical, Systems and Metal Engineering, \\ Ghent University, Technologiepark-Zwijnaarde 131, 9052 Ghent, Belgium; Joannes.Laveyne@UGent.be \\ 2 Department of Electronic Technology, Institute of Technology Baghdad, Middle Technical University, \\ Baghdad 10074, Iraq; mohannad.mnati@mtu.edu.iq \\ 3 Fluvius System Operator, Brusselsesteenweg 199, 9090 Melle, Belgium; Jan.VandeVyver@fluvius.be \\ 4 FlandersMake@UGent.be-Corelab EEDT-DC, Flanders Make, 9052 Ghent, Belgium \\ * Correspondence: dibozala.bozalakov@ugent.be (D.V.B.); lieven.vandevelde@ugent.be (L.V.); \\ Tel.: +32-471-636-520 (D.V.B.) \\ + These authors have contributed equally to this work.
}

Received: 30 September 2020; Accepted: 4 November 2020; Published: 6 November 2020

\begin{abstract}
The share of renewable energy is increasing because of environmental concerns and favorable economic conditions. The majority of the distributed energy resources, connected to the low-voltage grid, are inverter-connected units. These inverters are controlled by using specially developed control strategies to determine the power injection between the primary source and the grid. In the past, the connection of distributed energy resources was based on the connect-and-forget principle, but this approach leads to severe power quality problems. Nowadays, more sophisticated control strategies need to be developed, so that ancillary services can be provided to the distribution system operator, which will allow further increase of renewable share in the distribution grids. This article examines the technical capabilities of the three-phase damping control strategy to provide ancillary services to the distribution system operator. Besides the three-phase damping control strategy, the article also compares the classical positive-sequence control strategy. Active power drooping and reactive power exchange are combined with these control strategies and the effect on the annual energy production, power quality, and grid performance is assessed. The simulations are conducted on a Matlab/OpenDSS platform in a time series simulations.
\end{abstract}

Keywords: control strategy; penetration level; overvoltages; voltage unbalance; ancillary services

\section{Introduction}

In the recent years, the share of the distributed energy resources (DER) in the distribution grids has been growing continuously, due to environmental and economical concerns. The decreasing cost of photovoltaic (PV) systems accelerates the penetration of DER even more compared to previous years [1]. The electric power system has been developed as a one-way system, meaning that power flows in one direction, i.e., from the source to the load. By integrating DERs closer to the customers, reverse power flows may occur when there is lack of demand. Therefore, the distribution system operators (DSO) may face power quality challenges such as overvoltages. Due to the single-phase DER and asymmetrical loading voltage unbalance appears, which additionally decreases the hosting capacity of the low-voltage (LV) feeders [2]. 
There are several solutions for the DSOs to prevent power quality issues. A radical measure to mitigate the overvoltages and voltage unbalance is grid reinforcement for feeders. However, it is not preferred due to it its high cost and it is not practical for large-scale upgrades. Special equipment like dynamic voltage restorers (DVR) and distribution static compensators (DSTATCOM) can be installed to improve the power quality, but these devices are installed at medium voltage (MV) grid near the LV grids with high penetration level of DERs [3,4]. This implies that such a solution will not effectively solve nor mitigate problems with power quality at the end of the low-voltage buses. Furthermore, if similar problems occur in another LV grid connected to the same MV feeder but further geographically located from the DSTATCOM, the impact of the latter one will be small. Therefore, another optimal placement of these devices must be found and reinstalled [5]. On-load tap changers (OLTC) are very efficient devices for overvoltage mitigation, but since phase decoupled OLTC are not commercially popular, the voltage unbalance still remains unsolved. In addition, OLTCs might be able to solve overvoltages in saturated feeders, but they might cause undervoltages in other feeders.

As mentioned earlier, in order for the DSO to mitigate power quality problems, sometimes dedicated equipment like DSTATCOMs, dynamic voltage restorers (DVR), active power filters (APF), unified power factor correctors (UPFC) and OLTC may need to be installed. Nevertheless, if this device stops providing its service due to faults, the power quality problems will appear again. Another option is provision of ancillary services by the DERs themselves [6,7]. Unlike the dedicated equipment, the DERs are distributed across the LV grid and they can provide these ancillary services only when power quality improvement is needed [8]. Furthermore, the large number of DERs and the possible provision of ancillary services will increase the redundancy and thus reliability of the distribution grid and help the DSO to better maintain the power quality in their distribution grid.

In recent years, many research is carried out, which examines the ancillary services for voltage control provided by inverter-connected DERs and reactive power. Fixed power factor (FPF), variable power factor $(\mathrm{PF})$, and volt/var control are control strategies that have been developed and examined in [9-11]. Nevertheless, due to the high ratios of $R / X$ in LV grids, the reactive power is very ineffective. This is very well demonstrated in [12].

Usually, DERs are designed to inject all energy into the distribution grid to maximise the profit. Nevertheless, during peak production and low loading periods, some active power drooping can be used to achieve a more effective voltage control, compared to the reactive power exchange. This eventually leads to some loss for the prosumer, which will extend the payback period of the investment. To reduce the curtailed active power, a battery energy storage system (BESS) can be incorporated in the DER. BESSs have a great potential to help with the power quality improvement in many aspects such as peak shaving, overvoltage mitigation, and voltage unbalance mitigation [13-17]. In addition to that, BESS are capable of providing fast transient response during fast solar irradiance change and dips [18]. Feeder loss reduction in unbalanced LV grids is reported in [19,20]. Despite these great qualities, BESSs have their own power limitations, which have to be considered when integrated in DERs [21]. Furthermore, they can represent a substantial cost to the total system and sometimes it is hard to make a good business case and attract prosumers to invest in storage and provide ancillary services [22-25].

This article investigates the performance of different control strategies, where the voltage control is implemented by means of active power drooping and reactive power exchange. These strategies are combined with the classical positive-sequence control strategy. In order to address the voltage unbalance, active power drooping is implemented in the three-phase damping control strategy. The later one is capable of mitigating the voltage unbalance by acting resistively towards the zero- and negative-sequence voltage components. The impact on the power quality, injected annual energy and grid performance are used as key performance indicators of the examined control strategies as well as their combinations for their potential to provide ancillary services to the DSO.

The remainder of the article is organized as follows. In Section 2, a detailed description of the active power drooping, reactive power voltage control is given as well as an overview of the mathematical 
models of the positive-sequence and the three-phase damping control strategies. In Section 3 , the used simulation platform is described together with the LV grid and input data. In this section, the obtained simulation results of the different control strategies are presented. Finally, in Section 4, the conclusions are drawn.

\section{Control Strategies Description}

This section provides the theoretical foundation of the article. In it, a detailed mathematical description of all control strategies used in the article is provided. Latter, the numerical models are used in the developed simulation platform to assess their performance.

\subsection{Active Power Drooping}

When high solar irradiance is present, DERs generate maximum power. If the penetration level of renewables is high, the excessive power production combined with less loading may lead to power quality problems like overvoltages and voltage unbalance. This will lead to temporarily disconnection of DERs so that safe operation of the LV grid is preserved. This is known as active power curtailment, and it will lead to some financial losses to the prosumer due to the lost renewable energy injection. An appropriate solution for this problem is the active power drooping. This solution relies on measurements at the inverter terminals like injected current and grid voltages as implemented in [26]. Based on these measurements, the active power drooping is calculated and some active power curtailment is applied. Although active power is curtailed, this solution is still able to keep the DER connected to the grid and renewable energy is being injected into it, but most importantly, the quality of the power is not deteriorated. Some of the outcomes of the project INCREASE [27] are published in [28] and the results showed that the droop-based active power curtailment is able to improve the annual energy production with almost $50 \%$ compared to the hard power curtailment. Therefore, the active power curtailment is a more desirable solution when overvoltages and maximising the penetration level of renewables is concerned. Furthermore, because of its effectiveness, simplicity, and reliability, the need of supervisory control like multi-agent systems and coordinated control can be omitted.

The active power droop controller measures the root mean square (rms) values of the grid voltages $v_{g}$ at the inverter terminals. If a three-phase inverter is used, the droop controller uses the maximum of the phase voltages to ensure a safe and reliable operation. The droop controller is presented in Figure 1 and the final value of the drooped power $p_{\mathrm{dc}}$ is described mathematically by the following piecewise linear function:

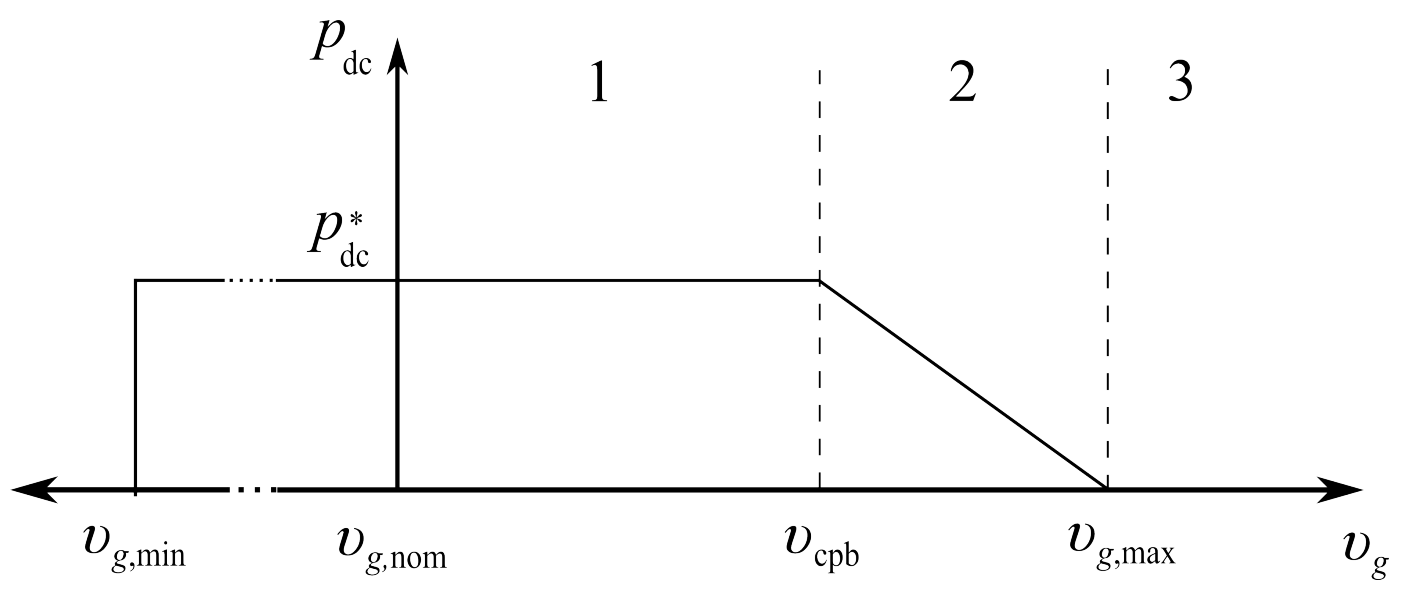

Figure 1. Active power drooping based on the work in [29]. 


$$
p_{\mathrm{dc}}=\left\{\begin{array}{l}
0, \text { if }\left|\underline{v}_{g}\right|<v_{g, \min } \\
p_{\mathrm{dc}}^{\bullet},\left|\underline{v}_{g}\right| \leq v_{\mathrm{cpb}} \\
p_{\mathrm{dc}}^{\bullet}\left(1-\frac{\left|\underline{v}_{g}\right|-v_{\mathrm{cpb}}}{v_{g, \max }-v_{\mathrm{cpb}}}\right), \text { if } v_{\mathrm{cpb}}<\left|\underline{v}_{g}\right| \leq v_{g, \max } \\
0, \text { if }\left|\underline{v}_{g}\right|>v_{g, \max }
\end{array}\right.
$$

where $v_{g, \min }$ and $v_{g, \max }$ are the minimum and maximum grid voltages, respectively. To comply with EN50160 [30], these parameters are set to $v_{g, \min }=0.9$ and $v_{g, \max }=1.1 \mathrm{p} . \mathrm{u}$. The constant power band is set by $v_{\mathrm{cpb}}$ and in this case equals to $1.06 \mathrm{p}$.u. In this work, it is assumed that the power electronic inverter has an efficiency of $100 \%$ and then the available power at the dc side is equal to the injected power at the ac side, hence, $p_{\mathrm{dc}}^{\bullet}=p_{\mathrm{ac}}$. Index " $\bullet$ " denotes the available power at the dc side, which can vary from 0 to the nominal power $p_{\mathrm{dc}, \text { nom. }}$. The parameter $p_{\mathrm{dc}, \text { nom }}$ depends on the power ratings of the primary source (photovoltaic system, wind turbine, small combined heat and power (CHP), etc.). The conditioning algorithm that ensures maximum power harvesting called a maximum power point tracking algorithm is also neglected because it is out of the scope of this work.

\subsection{Reactive Power Exchange by Using a Variable Power Factor}

In order for the DER to provide some voltage control, grid standards have different recommendations for reactive power exchange. The standard used in [31] recommends using distributed generation (DG) units with power lower than $3.86 \mathrm{~kW}$ to provide voltage control with power factor (PF) of 0.95 while the PF for higher power DER is 0.9. In Europe, the most common reactive power support is the variable power factor control. It calculates the PF as a function of the exchanged active power and its graphical representation can be seen in Figure 2 while the mathematical model can be written as follows.

$$
\mathrm{PF}=\left\{\begin{array}{l}
1, \text { if } p_{\mathrm{ac}}<0.5 p_{\mathrm{dc}, \text { nom }} \\
1-\frac{p_{\mathrm{ac}}-0.5 p_{\mathrm{dc}, \text { nom }}}{p_{\mathrm{dc}, \text { nom }}-0.5 p_{\mathrm{dc}, \text { nom }}} \Delta \mathrm{PF}
\end{array}\right.
$$

where $\triangle \mathrm{PF}$ is the desired deviation of the nominal PF. As long as the power is below the half of the nominal power, the DER injects power with a unity PF. If the exchanged power exceeds half of the nominal power, then the PF differs from 1 and finally it becomes $0.9(0.95)$ at full power. A disadvantage of this reactive power support is that reactive power is always exchanged whether or not the grid voltage needs to be regulated. This introduces extra losses in the low voltage grid because of the constant reactive power flow.

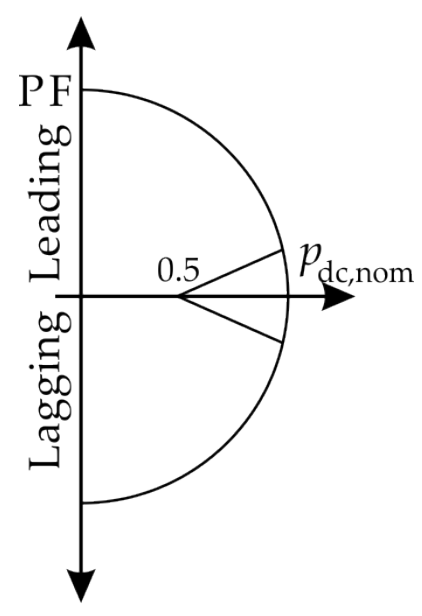

Figure 2. Variable power factor control strategy for voltage control based on the power ratings of the inverter. 


\subsection{Positive-Sequence Control Strategy}

The control strategies for the majority of the commercially available three-phase, inverter-connected DERs is based on positive-sequence current injection. This is because of the fact that the most common three-phase angle detection techniques are based on phase locked loop (PLL), which use a synchronous reference frame [32]. In other words, the three-phase PLLs use a coordinate transformation from $a b c$ to $d q$ [12] and, therefore, the output signals of these PLLs have phase angles corresponding to the positive-sequence component of the grid voltage. If it is assumed that only fundamental components are used, the analytical model of the positive-sequence control strategy can then be written as

$$
\underline{v}_{x}=\left|\underline{v}_{x}\right| \exp \left(j \theta_{x}\right)
$$

where $\underline{v}_{x}$ is the rms value of the phase voltage, $\left|\underline{v}_{x}\right|$ its magnitude, and $\theta_{x}$ its respective phase angle. Then, the exchanged sequence currents $\underline{i}_{0}, \underline{i}_{1}$, and $\underline{i}_{2}$ can be written as

$$
\left[\begin{array}{l}
\underline{i}_{0} \\
\underline{i}_{1} \\
\underline{i}_{2}
\end{array}\right]=\left[\begin{array}{ccc}
0 & 0 & 0 \\
0 & g_{1} & 0 \\
0 & 0 & 0
\end{array}\right]\left[\begin{array}{l}
\underline{v}_{0} \\
\underline{v}_{1} \\
\underline{v}_{2}
\end{array}\right]
$$

where $\underline{v}_{0}, \underline{v}_{1}$ and $\underline{v}_{2}$ are the zero-, positive-, and the negative-sequence voltage components. Parameter $g_{1}$ is the fundamental input conductance, which is described later in this section. Equation (4) can be transformed into phase quantities by using

$$
\left[\begin{array}{c}
\underline{i}_{a} \\
\underline{i}_{b} \\
\underline{i}_{c}
\end{array}\right]=T^{-1}\left[\begin{array}{ccc}
0 & 0 & 0 \\
0 & g_{1} & 0 \\
0 & 0 & 0
\end{array}\right] T\left[\begin{array}{l}
\underline{v}_{a} \\
\underline{v}_{b} \\
\underline{v}_{c}
\end{array}\right]
$$

where $T$ is the transformation matrix from phase quantities $(a, b, c)$ to symmetrical components $(0,1,2)$. Consequently, the following equations for the phase currents are obtained,

$$
\begin{aligned}
& \underline{i}_{a}=\frac{1}{3} g_{1}\left\{\underline{v}_{a}+a \underline{v}_{b}+a^{2} \underline{v}_{c}\right\} \\
& \underline{i}_{b}=\frac{1}{3} g_{1}\left\{a^{2} \underline{v}_{a}+\underline{v}_{b}+a \underline{v}_{c}\right\} \\
& \underline{i}_{c}=\frac{1}{3} g_{1}\left\{a \underline{v}_{a}+a^{2} \underline{v}_{b}+\underline{v}_{c}\right\}
\end{aligned}
$$

with $a=e^{\mathrm{j} 2 \pi / 3}$.

$$
\begin{aligned}
& \underline{i}_{a}=\frac{1}{3}\left\{g_{1}\left[\left|\underline{v}_{a}\right| e^{\mathrm{j} \theta_{a}}+\left|\underline{v}_{b}\right| e^{\mathrm{j}\left(\theta_{b}+\frac{2 \pi}{3}\right)}+\left|\underline{v}_{c}\right| e^{\mathrm{j}\left(\theta_{c}-\frac{2 \pi}{3}\right)}\right]\right\} \\
& \underline{i}_{b}=\frac{1}{3}\left\{g_{1}\left[\left|\underline{v}_{b}\right| e^{\mathrm{j} \theta_{b}}+\left|\underline{v}_{a}\right| e^{\mathrm{j}\left(\theta_{a}-\frac{2 \pi}{3}\right)}+\left|\underline{v}_{c}\right| e^{\mathrm{j}\left(\theta_{c}+\frac{2 \pi}{3}\right)}\right]\right\} \\
& \underline{i}_{c}=\frac{1}{3}\left\{g_{1}\left[\left|\underline{v}_{c}\right| e^{\mathrm{j} \theta_{c}}+\left|\underline{v}_{a}\right| e^{\mathrm{j}\left(\theta_{a}+\frac{2 \pi}{3}\right)}+\left|\underline{v}_{b}\right| e^{\mathrm{j}\left(\theta_{b}-\frac{2 \pi}{3}\right)}\right]\right\}
\end{aligned}
$$

where $\underline{v}_{a}, \underline{v}_{b}, \underline{v}_{c}, \theta_{a}, \theta_{b}$, and $\theta_{c}$ are the respective phase voltages and angles, while the fundamental input conductance $g_{1}$ ensures the power balance between the ac and the dc side and it is calculated by using the following equation.

$$
g_{1}=\frac{3 p_{\mathrm{dc}}^{\bullet}}{\sum\left|\underline{v}_{x}\right|^{2}+2 \sum_{x \neq y}\left|\underline{v}_{x}\right|\left|\underline{v}_{y}\right| \cos \left(\theta_{\mathrm{x}}-\theta_{\mathrm{y}}-\frac{2 \pi}{3}\right)}
$$


Additional information about the fundamental conductance and its mathematical extraction can be found in $[12,26]$.

\subsection{Three-Phase Damping Control Strategy}

As mentioned earlier, voltage unbalance is the second power quality problem in LV grids, which appears in areas with high penetration of DERs. In order to address this issue, the three-phase damping control strategy can be used. This control strategy is examined in $[26,33]$ and is able to mitigate the voltage unbalance at the point of common coupling (PCC). The reaction of the damping control strategy is to behave resistively towards the zero- and negative-sequence voltage components [12,26,34]. Therefore, the exchanged symmetrical component currents can be expressed as follows,

$$
\left[\begin{array}{l}
\underline{i}_{0} \\
\underline{i}_{1} \\
\underline{i}_{2}
\end{array}\right]=\left[\begin{array}{ccc}
g_{d} & 0 & 0 \\
0 & g_{1} & 0 \\
0 & 0 & g_{d}
\end{array}\right]\left[\begin{array}{l}
\underline{v}_{0} \\
\underline{v}_{1} \\
\underline{v}_{2}
\end{array}\right]
$$

where $g_{d}$ is the fundamental damping conductance of the inverter and it sets the resistive behavior towards both the zero- and negative-sequence components. By further developing Equation (9) to phase quantities, the following expression is obtained.

$$
\left[\begin{array}{l}
\underline{i}_{a} \\
\underline{i}_{b} \\
\underline{i}_{c}
\end{array}\right]=T^{-1}\left[\begin{array}{ccc}
g_{d} & 0 & 0 \\
0 & g_{1} & 0 \\
0 & 0 & g_{d}
\end{array}\right] T\left[\begin{array}{l}
\underline{v}_{a} \\
\underline{v}_{b} \\
\underline{v}_{c}
\end{array}\right]
$$

By following the same procedure as the positive-sequence control strategy, the currents injected by the damping control strategy can be described mathematically by the following set of equations.

$$
\begin{aligned}
& \underline{i}_{a}=\frac{1}{3}\left\{g_{1}\left[\left|\underline{v}_{a}\right| e^{\mathrm{j} \theta_{a}}+\left|\underline{v}_{b}\right| e^{\mathrm{j}\left(\theta_{b}+\frac{2 \pi}{3}\right)}+\left|\underline{v}_{c}\right| e^{\mathrm{j}\left(\theta_{c}-\frac{2 \pi}{3}\right)}\right]+g_{d}\left[2\left|\underline{v}_{a}\right| e^{\mathrm{j} \theta_{a}}-\left|\underline{v}_{b}\right| e^{\mathrm{j}\left(\theta_{b}+\frac{2 \pi}{3}\right)}-\left|\underline{v}_{c}\right| e^{\mathrm{j}\left(\theta_{c}-\frac{2 \pi}{3}\right)}\right]\right\} \\
& \underline{i}_{b}=\frac{1}{3}\left\{g_{1}\left[\left|\underline{v}_{b}\right| e^{\mathrm{j} \theta_{b}}+\left|\underline{v}_{a}\right| e^{\mathrm{j}\left(\theta_{a}-\frac{2 \pi}{3}\right)}+\left|\underline{\mathfrak{v}}_{c}\right| e^{\mathrm{j}\left(\theta_{c}+\frac{2 \pi}{3}\right)}\right]+g_{d}\left[2\left|\underline{v}_{b}\right| e^{\mathrm{j} \theta_{b}}-\left|\underline{v}_{a}\right| e^{\mathrm{j}\left(\theta_{a}-\frac{2 \pi}{3}\right)}-\left|\underline{v}_{c}\right| e^{\mathrm{j}\left(\theta_{c}+\frac{2 \pi}{3}\right)}\right]\right\} \\
& \underline{i}_{c}=\frac{1}{3}\left\{g_{1}\left[\left|\underline{v}_{c}\right| e^{\mathrm{j} \theta_{c}}+\left|\underline{v}_{a}\right| e^{\mathrm{j}\left(\theta_{a}+\frac{2 \pi}{3}\right)}+\left|\underline{v}_{b}\right| e^{\mathrm{j}\left(\theta_{b}-\frac{2 \pi}{3}\right)}\right]+g_{d}\left[2\left|\underline{\underline{v}}_{c}\right| e^{j \theta_{c}}-\left|\underline{v}_{a}\right| e^{\mathrm{j}\left(\theta_{a}+\frac{2 \pi}{3}\right)}-\left|\underline{v}_{b}\right| e^{\mathrm{j}\left(\theta_{b}-\frac{2 \pi}{3}\right)}\right]\right\}
\end{aligned}
$$

When the three-phase damping control strategy is used in injection mode, parameters $g_{1}$ and $g_{d}$ have opposite signs. The positive-sequence power injection is determined by the terms related to $g_{1}$. The fundamental input conductance is calculated by a dc-bus controller to maintain the power balance between the ac and dc sides. The zero- and negative-current injection is set by the terms related to $g_{d}$. Additional information regarding the analytical expressions of the three-phase damping control strategy can be found in [26].

For the practical implementation of the control strategy, a dc-bus voltage controller is utilized to maintain the power balance between the dc and ac side. The output signal generated by this controller is the fundamental conductance $g_{1}$ of the VSI [35]. The analytical representation of this parameter can be expressed in the following manner.

$$
\begin{aligned}
g_{1}=\frac{3 p_{\mathrm{dc}}^{\bullet}}{\sum\left|\underline{v}_{x}\right|^{2}+2 \sum_{x \neq y}\left|\underline{v}_{x}\right|\left|\underline{v}_{y}\right| \cos \left(\theta_{\mathrm{x}}-\theta_{\mathrm{y}}-\frac{2 \pi}{3}\right)} & \\
& -2 g_{d} \frac{\sum\left|\underline{v}_{x}\right|^{2}-\sum_{x \neq y}\left|\underline{v}_{x}\right|\left|\underline{v}_{y}\right| \cos \left(\theta_{\mathrm{x}}-\theta_{\mathrm{y}}-\frac{2 \pi}{3}\right)}{\sum\left|\underline{v}_{x}\right|^{2}+2 \sum_{x \neq y}\left|\underline{v}_{x}\right|\left|\underline{v}_{y}\right| \cos \left(\theta_{\mathrm{x}}-\theta_{\mathrm{y}}-\frac{2 \pi}{3}\right)}
\end{aligned}
$$


The first fraction of (12) calculates the positive-sequence power, which determines the amount of the injected active power with the grid, while the second fraction is responsible for compensating the power of the zero- and negative-sequence components that are flowing through the inverter. The three-phase damping control strategy is able to mitigate the voltage unbalance at the point of common connection by exchanging asymmetrical currents with the grid. From the presented analytical expressions, it can be seen that these asymmetrical currents are based on the symmetrical component theory and ensures a natural mitigation of the voltage unbalance, which affects not only the rms voltage values but also the phase angles. The asymmetrical current injection is caused by the resistive behavior of the control strategy, which results in larger current injection in the phase with lower voltage and smaller currents in the phases with higher voltage. Thus the voltage unbalance is mitigated. This resistive behavior is determined by $g_{d}$, which in practice is calculated by using the nominal ratings of the DER:

$$
G_{d}=\frac{P_{\mathrm{dc}, \text { nom }}}{V_{\text {nom }}^{2}}
$$

where $P_{\mathrm{dc} \text {,nom }}$ is the nominal power of the inverter and $V_{\text {nom }}$ is the nominal grid voltage. In a p.u. system the damping conductance is expressed as

$$
g_{d}=\frac{P_{\mathrm{dc}, \text { nom }} / P_{\mathrm{dc}, \mathrm{base}}}{V_{\text {nom }}^{2} / V_{\mathrm{base}}^{2}}
$$

where $P_{\mathrm{dc}, \text { base }}$ is the base power of the power electronic inverter and $V_{\text {base }}$ is the base value of the grid voltage.

\subsection{Three-Phase Damping Control Strategy: Negative-Sequence Component Mitigation}

Usually the three-phase DERs are connected via a three-phase, three-wire connection and inject only positive-sequence currents. Therefore, by using such a system, only the negative-sequence component can be impacted. In addition, EN50160 [30] recommends only limits to the negative voltage unbalance factor, which is the ratio of the negative- to positive-sequence voltage components and no recommendation to the zero-sequence components are given whatsoever. In order to make the three-phase damping control strategy compliant to act resistively only to the negative-sequence voltage component, a modification in Equation (10) can be made so that only the negative-sequence component is impacted by the three-phase damping control strategy:

$$
\left[\begin{array}{l}
\underline{i}_{a} \\
\underline{i}_{b} \\
\underline{i}_{c}
\end{array}\right]=T^{-1}\left[\begin{array}{ccc}
0 & 0 & 0 \\
0 & g_{1} & 0 \\
0 & 0 & g_{d 2}
\end{array}\right] T\left[\begin{array}{l}
\underline{v}_{a} \\
\underline{v}_{b} \\
\underline{v}_{c}
\end{array}\right]
$$

By following the same procedure as the positive-sequence control strategy, the currents injected by the damping control strategy for negative-sequence component mitigation are obtained as follows.

$$
\begin{aligned}
& \underline{i}_{a}=\frac{1}{3}\left\{g_{1}\left[\left|\underline{v}_{a}\right| e^{\mathrm{j} \theta_{a}}+\left|\underline{v}_{b}\right| e^{\mathrm{j}\left(\theta_{b}+\frac{2 \pi}{3}\right)}+\left|\underline{v}_{c}\right| e^{\mathrm{j}\left(\theta_{c}-\frac{2 \pi}{3}\right)}\right]+g_{d 2}\left[\left|\underline{v}_{a}\right| e^{\mathrm{j} \theta_{a}}+\left|\underline{v}_{b}\right| e^{\mathrm{j}\left(\theta_{b}-\frac{2 \pi}{3}\right)}+\left|\underline{v}_{c}\right| e^{\mathrm{j}\left(\theta_{c}+\frac{2 \pi}{3}\right)}\right]\right\} \\
& \underline{i}_{b}=\frac{1}{3}\left\{g_{1}\left[\left|\underline{v}_{b}\right| e^{\mathrm{j} \theta_{b}}+\left|\underline{v}_{a}\right| e^{\mathrm{j}\left(\theta_{a}-\frac{2 \pi}{3}\right)}+\left|\underline{v}_{c}\right| e^{\mathrm{j}\left(\theta_{c}+\frac{2 \pi}{3}\right)}\right]+g_{d 2}\left[\left|\underline{v}_{b}\right| e^{\mathrm{j} \theta_{b}}+\left|\underline{v}_{a}\right| e^{\mathrm{j}\left(\theta_{a}+\frac{2 \pi}{3}\right)}+\left|\underline{v}_{c}\right| e^{\mathrm{j}\left(\theta_{c}-\frac{2 \pi}{3}\right)}\right]\right\} \\
& \underline{i}_{c}=\frac{1}{3}\left\{g_{1}\left[\left|\underline{v}_{c}\right| e^{\mathrm{j} \theta_{c}}+\left|\underline{v}_{a}\right| e^{\mathrm{j}\left(\theta_{a}+\frac{2 \pi}{3}\right)}+\left.\left|\underline{v}_{b}\right|\right|^{\mathrm{j}\left(\theta_{b}-\frac{2 \pi}{3}\right)}\right]+g_{d 2}\left[\left|\underline{v}_{c}\right| e^{\mathrm{j} \theta_{c}}+\left|\underline{v}_{a}\right| e^{\mathrm{j}\left(\theta_{a}-\frac{2 \pi}{3}\right)}+\left|\underline{v}_{b}\right| e^{\mathrm{j}\left(\theta_{b}+\frac{2 \pi}{3}\right)}\right]\right\}
\end{aligned}
$$


The power balance of this adapted control strategy differs from the expression given in Equation (12). The fundamental input conductance, which includes the compensation only of the negative-sequence component is written as,

$$
\begin{aligned}
g_{1}=\frac{3 p_{\mathrm{dc}}^{\bullet}}{\sum\left|\underline{v}_{x}\right|^{2}+2 \sum_{x \neq y}\left|\underline{v}_{x}\right|\left|\underline{v}_{y}\right| \cos \left(\theta_{\mathrm{x}}-\theta_{\mathrm{y}}-\right.} & \left.\frac{2 \pi}{3}\right) \\
& +g_{d 2} \frac{\sum\left|\underline{v}_{x}\right|^{2}+\sum_{x \neq y}\left|\underline{v}_{x}\right|\left|\underline{v}_{y}\right| \cos \left(\theta_{\mathrm{x}}-\theta_{\mathrm{y}}+\frac{2 \pi}{3}\right)}{\sum\left|\underline{v}_{x}\right|^{2}+2 \sum_{x \neq y}\left|\underline{v}_{x}\right|\left|\underline{v}_{y}\right| \cos \left(\theta_{\mathrm{x}}-\theta_{\mathrm{y}}-\frac{2 \pi}{3}\right)}
\end{aligned}
$$

Although Equation (17) differs from Equation (12), the same interpretation of Equation (12) can be applied for this power balance expression. The damping conductance $g_{d 2}$ in p.u. value can be calculated by using Equation (14).

\subsection{Model Description}

In this section, a detailed description of the model built is presented. In order to perform asymmetrical power flow analyses in OpenDSS, single-phase domestic loads, single-phase, and three-phase DERs are used and described in this section. The single line diagram of the used topology as well as the DER placement are also discussed.

\subsubsection{Grid Data}

The performance evaluation of the considered control strategies and their combinations are tested by means of simulations on an existing LV grid, which is shown in Figure 3. This is an LV network in Suha, Slovenia, consisting of 78 nodes spread over several feeders. The MV/LV transformer of Dyn type has a nominal power of $250 \mathrm{kVA}$, short circuit voltage of $4 \%$ while the no load losses are $325 \mathrm{~W}$ and $3250 \mathrm{~W}$, respectively. The primary and secondary nominal voltages are $20 \mathrm{kV}$ and $0.4 \mathrm{kV}$, respectively. The voltages at the secondary side are set to be 1.05 p.u., which is a typical setting used by the DSO in order to avoid undervoltages to the most distant customers when high loading conditions are present.

\subsubsection{Load and DERs Data}

The considered LV grid consists of 78 nodes, and to each node three different loads are connected. All loads are considered to be household loads and they are generated by using the methodology proposed in [36]. Overall, 200 different single-phase domestic load profiles are generated and grouped in clusters of three, which are connected to each node to a different phase. They are grouped such that the relative deviation between the loads, at any time instance, is minimum. These clusters are connected to the different nodes. By clustering the loads, the difference in the average power at each node is very low, which will help to limit and keep the voltage unbalance below $2 \%$. In this article, all loads are assumed to have $P F=0.9$. All loads are $15 \mathrm{~min}$-based, and the sum of the apparent power of all loads is depicted in Figure 4. The load profiles are generated for one year, which gives a total of 35,136 values. 


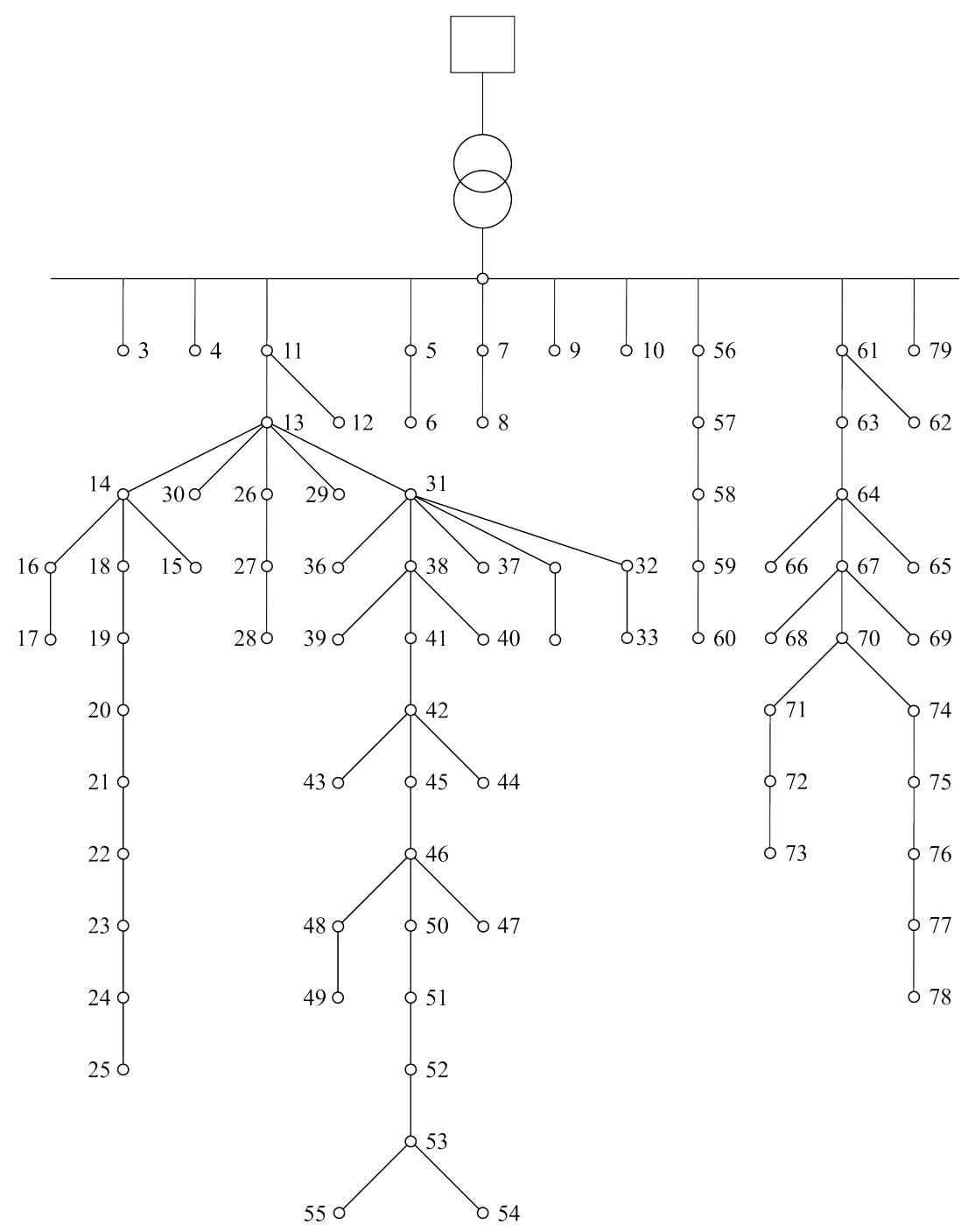

Figure 3. Feeder topology used to assess the performance the examined control strategies.

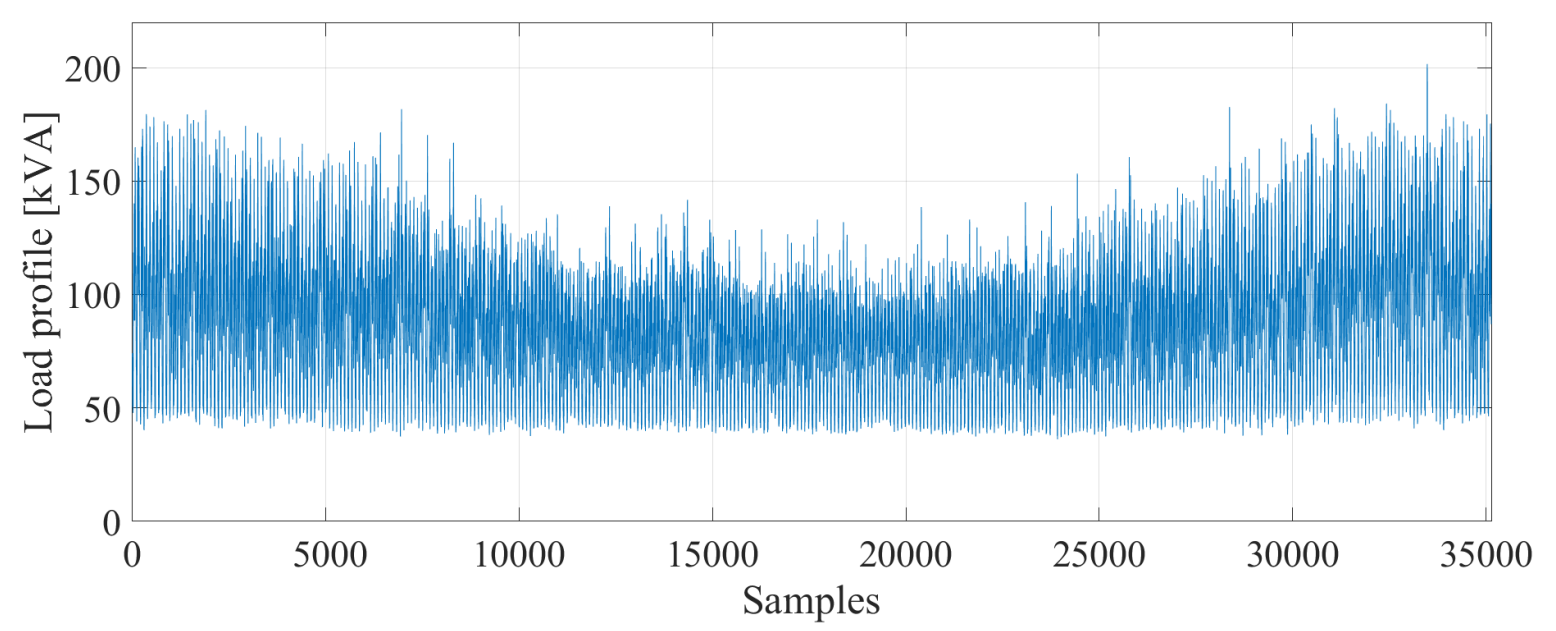

Figure 4. Aggregated load profile of all different single-phase load profiles.

In this article, 5 three-phase DERs and 14 single-phase DERs are considered to be connected in the $\mathrm{LV}$ grid. The rated active power and phase connections are presented in Table 1. The maximum power 
of the considered DERs is selected such that power quality problems like overvoltages occur at the most distant locations of the feeders when maximum solar irradiation is available. Note that, this power selection is done when all DERs are equipped with the classical non-drooped positive-sequence and single-phase control strategies. Therefore, further installation of new DERs is no longer possible. DERs with nominal power higher than $5 \mathrm{~kW}$ are interfaced via three-phase connection and can perform voltage control via active power drooping (unless otherwise specified). All DERs with rated power lower than $5 \mathrm{~kW}$ are equipped with variable $\mathrm{PF}$ as a function of the injected power. In this particular case, the total installed peak power is $214 \mathrm{~kW}$, which related to the nominal power of the MV/LV transformer gives a penetration level of $85 \%$. Solar irradiation profile based on real measurements is used as an input for all DERs. The normalized solar irradiation profile that is used to perform the power flows is depicted in Figure 5.

Table 1. Nominal power of distributed energy resource (DER) and storage capacity.

\begin{tabular}{cccccc}
\hline DERs & Rated Power & DERs & Rated Power & DERs & Rated Power \\
\hline DER $_{24}$ & $30 \mathrm{~kW}(\mathrm{Y})$ & $\mathrm{DER}_{13}$ & $3 \mathrm{~kW}(\mathrm{Y})$ & $\mathrm{DER}_{21}$ & $30 \mathrm{~kW}(\mathrm{Y})$ \\
$\mathrm{DER}_{47}$ & $44 \mathrm{~kW}(\mathrm{Y})$ & $\mathrm{DER}_{14}$ & $30 \mathrm{~kW}(\mathrm{Y})$ & $\mathrm{DER}_{22}$ & $30 \mathrm{~kW}(\mathrm{Y})$ \\
$\mathrm{DER}_{52}$ & $30 \mathrm{~kW}(\mathrm{Y})$ & $\mathrm{DER}_{15}$ & $30 \mathrm{~kW}(\mathrm{Y})$ & $\mathrm{DER}_{23}$ & $30 \mathrm{~kW}(\mathrm{Y})$ \\
$\mathrm{DER}_{59}$ & $30 \mathrm{~kW}(\mathrm{Y})$ & $\mathrm{DER}_{16}$ & $30 \mathrm{~kW}(\mathrm{Y})$ & $\mathrm{DER}_{45}$ & $30 \mathrm{~kW}(\mathrm{Y})$ \\
DER $_{70}$ & $30 \mathrm{~kW}(\mathrm{Y})$ & $\mathrm{DER}_{18}$ & $30 \mathrm{~kW}(\mathrm{Y})$ & $\mathrm{DER}_{49}$ & $30 \mathrm{~kW}(\mathrm{Y})$ \\
- & - & $\mathrm{DER}_{19}$ & $30 \mathrm{~kW}(\mathrm{Y})$ & $\mathrm{DER}_{50}$ & $30 \mathrm{~kW}(\mathrm{Y})$ \\
- & - & $\mathrm{DER}_{20}$ & $30 \mathrm{~kW}(\mathrm{Y})$ & $\mathrm{DER}_{54}$ & $30 \mathrm{~kW}(\mathrm{Y})$ \\
\hline
\end{tabular}

A few test cases are examined in order to compare the different results. The cases are defined as follows.

- In the first case $C 0$, the grid only consists of loads.

- In the second case $C 1$, all DERs inject their maximum power, and this case will be used as a reference case to check how much power is been curtailed or drooped.

- In the next case $C 2$, the classical hard curtailment is implemented together with voltage control based on reactive power exchange is in all DERs. Single-phase control strategy of this type is described in [12], while the three-phase positive-sequence control strategy is described in Section 2.3. More information about the implementation of the hard curtailment will be given later on in this section.

- The combination of active power drooping together with the positive-sequence control strategy forms case $C 3$ where only active power is considered to be drooped and injected. This control strategy is described in Sections 2.1 and 2.3.

- The drooped three-phase damping control strategy, which mitigates only the negative-sequence voltage components is assigned to case C4. The drooped part is described in Section 2.1. The analytical description of the damping control strategy is given in Section 2.5.

- Cases C5, C6, and C7 represent the modified three-phase drooped damping control strategy with initial damping conductance values of $g_{d}=3$ p.u. $g_{d}=10$ p.u., and $g_{d}=50$ p.u., respectively. In order to compare the difference in damping capabilities and power quality performance between test cases $C 4$ and $C 7$, the value of $g_{d 2}$ is chosen to be equal to 50 p.u., similarly to case $C 7$. 


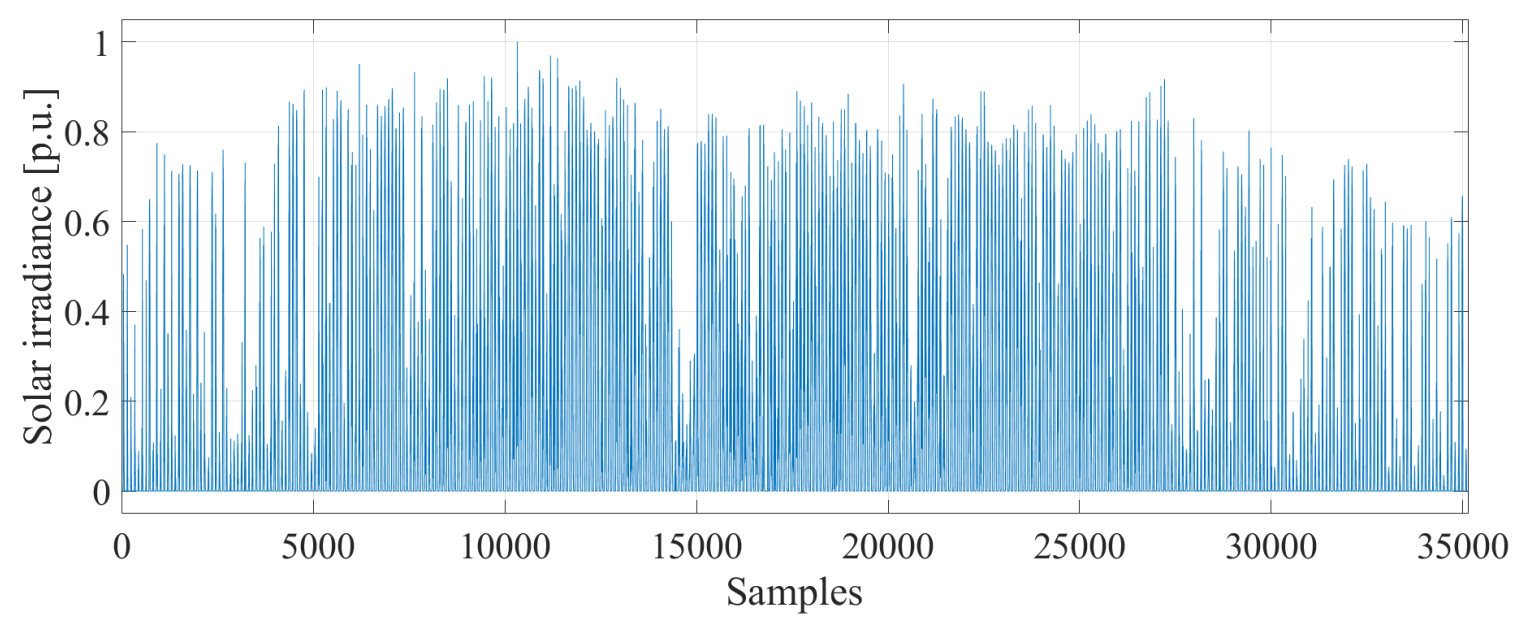

Figure 5. Solar irradiance profile used in the simulation model [37].

\section{Simulation Results}

In this section, a detailed description of the built simulation model is given. All data of the previous section, plus the described control strategies, are put into the model and the simulation results are obtained.

\subsection{Description of the OpenDSS Model}

The grid is simulated in a time series manner by using OpenDSS that is interfaced with Matlab. The single line diagram of the grid is depicted in Figure 3 and as can be seen there are 78 nodes. The location of the DER, rated power, and phase connection are shown as well. The majority of DER is single-phase connected with rated power between 2 and $5 \mathrm{kWp}$. Since the physical area of the grid is small, it is assumed that all DERs have the same solar irradiation. The solar irradiation profiles, presented in Figure 5 are provided by [37] and used by all DERs. The examined period is one year with a $15 \mathrm{~min}$ basis between the samples. As mentioned above, the power of all DERs is chosen such that overvoltages occur at the end of the longest feeders. The simulations are performed with time series and the corresponding values of the vectors of the solar irradiation and the load profiles are simulated.

Case $C 2$ represents the massively used positive-sequence control strategy with a variable PF as function of the active power and hard curtailment. Suppose that at some point nodes 54 to 52 experience overvoltages, then $\mathrm{DER}_{52}$ and $\mathrm{DER}_{54}$ will be turned off immediately for that time step and the simulation will move to the next step. This, however, will result in a large power curtailment, which actually may not happen in practice because of the discretisation of $15 \mathrm{~min}$. In practice, $\mathrm{DER}_{54}$ will turn off before $\mathrm{DER}_{52}$, because it is further connected from the MV/LV transformer. This might be sufficient to prevent the overvoltages and it may not be necessary to turn off $\mathrm{DER}_{52}$ at all. In order to overcome this disadvantage of the time series simulations and prevent false overvoltage tripping, an internal loop is introduced. This internal loop is accessed only if an overvoltage problem occurs. In this loop, the set power is increased gradually to the maximum set point, which will trip the DERs one by one in case of overvoltages and not all at once. Thus a more realistic behavior of the model is achieved and the curtailed power will not be overestimated.

Cases $C 3$ to $C 8$ use active power drooping as a function of the grid voltages, which requires a different approach to perform the power flow because OpenDSS does not have controllable DER strategies in its library. In [38], a four-step approach for implementing active power drooping in OpenDSS is proposed. In the first step, the normalized solar irradiation profile is multiplied with the rated power of the DERs as well as the load profiles. Then an asymmetrical power flow is performed in OpenDSS. In this step, the DERs do not droop any power, which will result in overvoltages. In the second step, the drooped power is calculated as a function of the grid voltages. As there is always 
some voltage unbalance present in the LV grid, the maximum among the phase voltages is chosen to calculate the injected power. In the third step, another power flow is ran with the new values of the drooped power. In the last step, a convergence check is performed based on predefined tolerance. The absolute error between the current values of the phase voltages and the previous values is made. If the result is lower that $0.023 \mathrm{~V}$ the simulation continues with the next time series. If this is not the case, the simulation repeats step 2. More information about the droop implementation can be found in [12] and the developed simulation model in [38]. In the last reference, the proposed combination of OpenDSS and Matlab is also compared with a Matlab and Simulink model. The results show very good agreement between the two models.

The total length of the solar and load vectors is 35,136 points while the node numbers are 78 . This results in a matrix of 78 rows and 35,136 columns. In order to avoid unnecessary data and figures, a box plot will be used to represent some of the obtained simulation results. First, each voltage matrix is concatenated from $78 \times 35,136$ to $1 \times 2,740,608$. The same is done also for negative-sequence unbalance factor $\left(\mathrm{VUF}_{2}\right)$ and zero-sequence unbalance factor $\left(\mathrm{VUF}_{0}\right)$.

The obtained simulation results of case $C 0$ are depicted in Figure 6 . All phase voltages are depicted in Figure $6 \mathrm{a}$ and as it can be seen, the mean phase voltages are within the standard limits set by [30]. Furthermore, even the outliers (the red plus signs) do not reach the bottom limit of the standard voltage band. In Figure $6 b$, the negative- and zero-sequence voltage unbalance factors are presented. The simulation results show that the mean value of $\mathrm{VUF}_{2}$ is lower than $0.2 \%$ while the outliers do not exceed $2 \%$. The outliers of $\mathrm{VUF}_{0}$ reach $2.8 \%$; however, there is no limit for this parameter in the currently acting standard. Based on the obtained simulation results, it can be concluded that the loads are properly distributed across the feeders because there are no power quality problems in the LV grid.

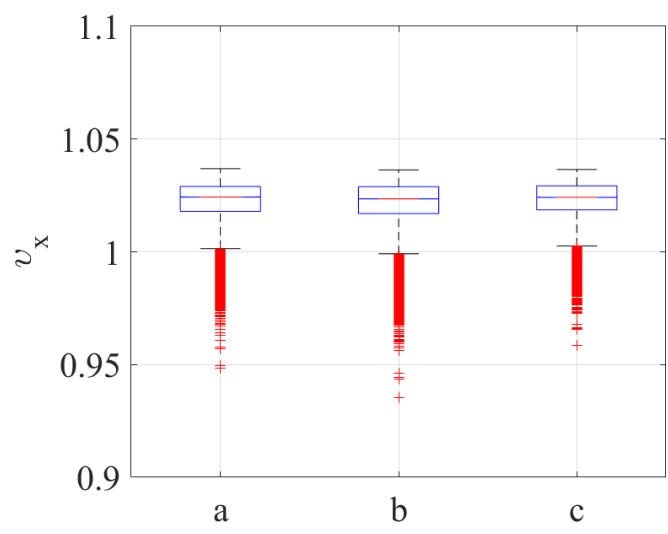

(a) rms values of all phase voltages in case $\mathrm{C} 0$

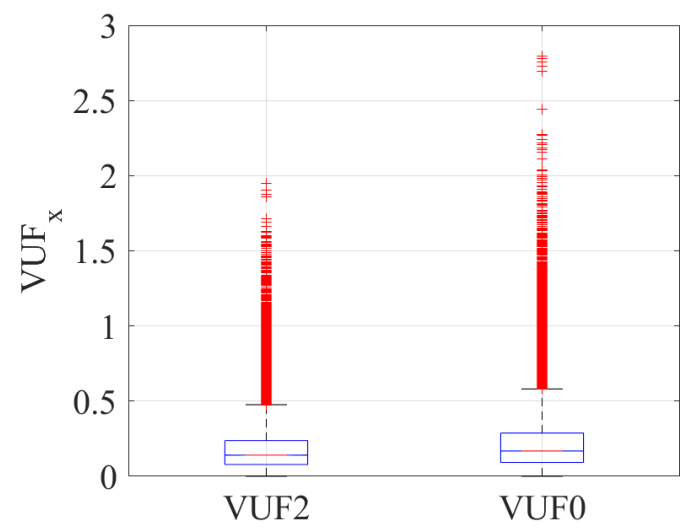

(b) $\mathrm{VUF}_{2}$ and $\mathrm{VUF}_{0}$ in case $\mathrm{CO}$

Figure 6. Concatenated results of the entire low-voltage (LV) grid when case $C 0$ is examined.

In Figure 7a, the phase voltages are depicted when no control is applied to all DERs whatsoever. Because of the high penetration level of DERs, severe overvoltages can be observed in all phases, which reach almost 1.17 p.u. The obtained simulation results of case $C 2$ are presented in Figure $7 \mathrm{~b}$. The mean values and the maximum deviations of the phase voltages are more or less the same as the previous case; however, the maximum values, reached by the outliers, are limited to 1.105 p.u.

The drooped three-phase positive-sequence control strategy performs active power drooping as function of the grid voltages and it is able to provide lower and safer rms voltage levels in all phases. Figure $7 \mathrm{c}$ shows that the maximum voltage deviations are slightly lower compared to case $C 2$ but the outliers barely reach 1.08 p.u. in phase $b$ while in the other two phases the maximum values are lower than 1.07 p.u. 
The obtained results of case 4 are presented in Figure $7 \mathrm{~d}$. In this case, only negative-sequence component mitigation is applied and as it can be seen, the maximum deviation of $\left|\underline{v}_{b}\right|$ is slightly wider compared to case $C 3$ and also the maximum outliers are slightly lower in phase $b$.

In Figure $8 \mathrm{a}-\mathrm{c}$, the drooped three-phase damping control strategy is examined with $g_{d}$ values of 3,10 , and 50 p.u. The simulation results show that the mean values of the phase voltages are rather the same for all three cases but the outliers are better equalized when a higher damping conductance value of 50 p.u. is used.

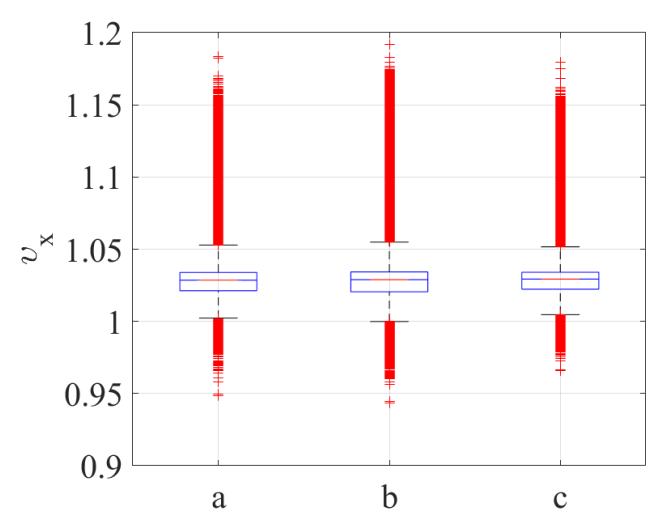

(a) rms values of all phase voltages in case $C 1$

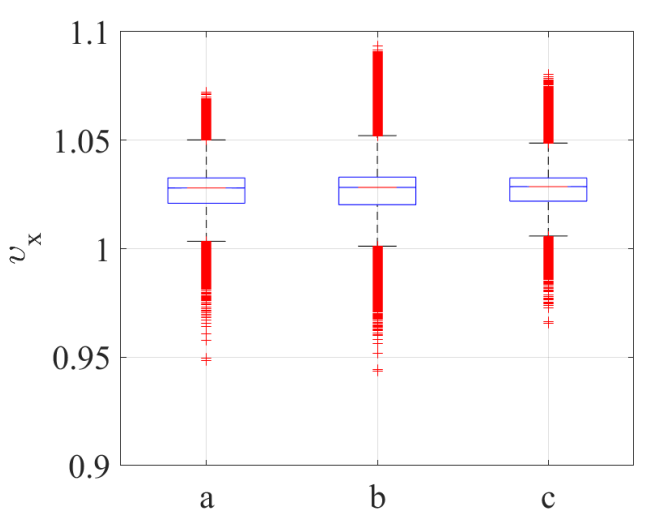

(c) rms values of all phase voltages in case $\mathrm{C} 3$

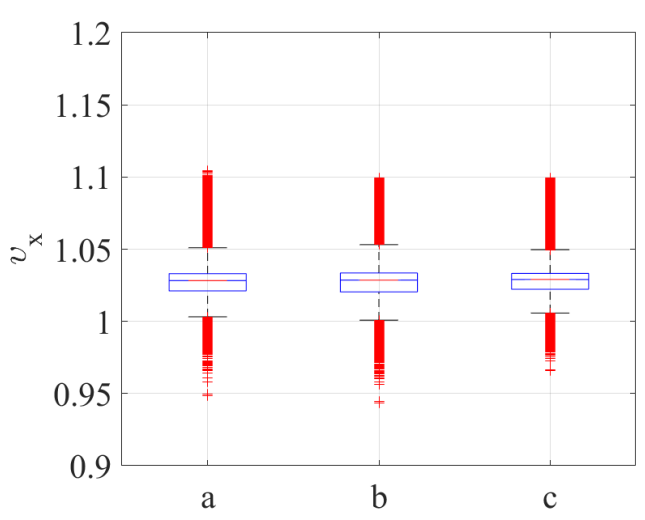

(b) rms values of all phase voltages in case $C 2$

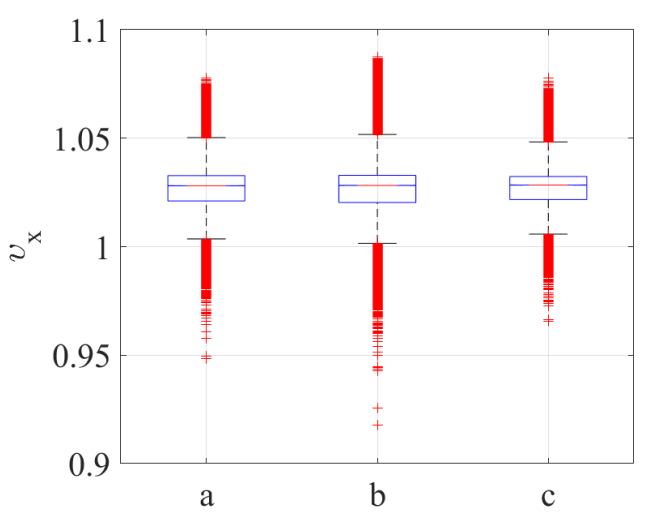

(d) rms values of all phase voltages in case $C 4$

Figure 7. Concatenated voltage results of the entire LV grid when cases $C 1$ to $C 4$ are examined.

The negative- and zero-sequence voltage unbalance factors of cases $C 1$ to $C 4$ are depicted in Figure $9 \mathrm{a}-\mathrm{d}$, respectively. Although case $\mathrm{C} 1$ does not consider any control of all DERs and overvoltages are present in all phases, $\mathrm{VUF}_{2}$ is smaller than $2 \%$, which means the power of the loads and DERs is more or less distributed equally among the three phases.

As cases $C 1$ to $C 3$ do not impact the sequence components, the range of the maximum deviations are $\mathrm{VUF}_{2}=0.6 \%$ and $\mathrm{VUF}_{0}=0.7 \%$. The outliers of $\mathrm{VUF}_{2}$ for these cases also do not exceed $2 \%$ and the outliers of $\mathrm{VUF}_{0}$ are all lower than $3 \%$.

Case $C 4$ impacts only the negative sequences, and as it can be seen in Figure 9d, the mean value of $\mathrm{VUF}_{2}$ is decreased down to $0.12 \%$, while in the previous cases these values were around $0.2 \%$. The maximum deviations of the quartiles are also decreased down to $0.35 \%$, while the outliers hardly exceed $1.6 \%$. The obtained simulation results of $\mathrm{VUF}_{0}$ are the same as the previous cases.

In Figure 10 the obtained simulation results for cases $C 5$ to $C 7$ are depicted. By increasing the damping conductance from 3 p.u. to 50 p.u. in cases $C 5$ to $C 7$, it can be seen that the mean values of both unbalance factors decrease as well as their maximum deviation ranges. The outliers are also decreased and barely exceed $1.8 \%$ in all cases. 


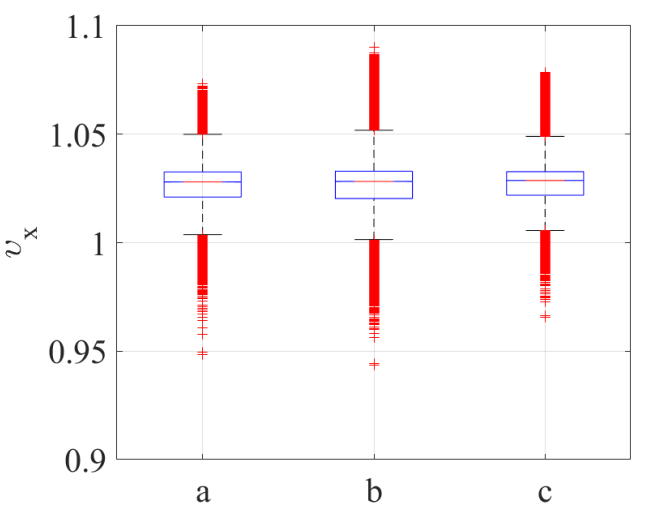

(a) rms values of all phase voltages in case $\mathrm{C5}$

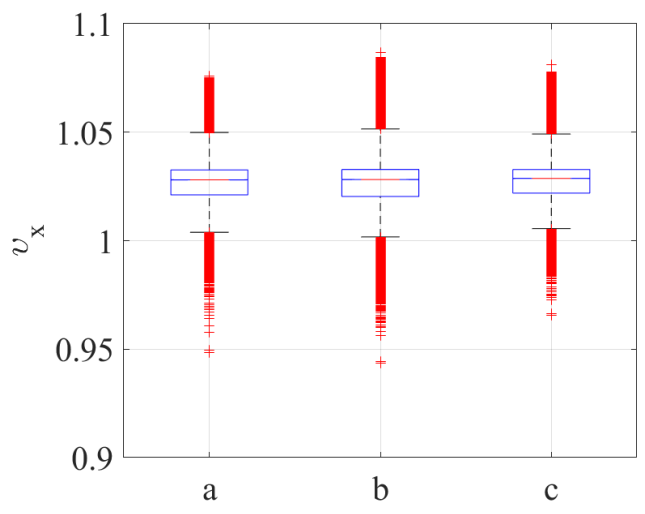

(b) rms values of all phase voltages in case $\mathrm{C6}$

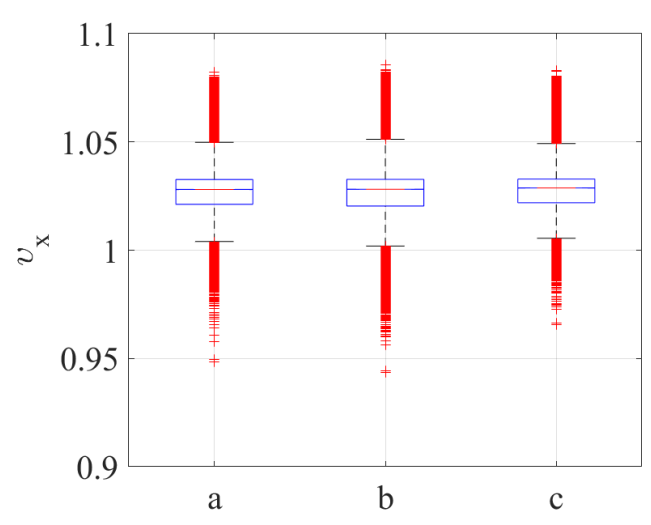

(c) rms values of all phase voltages in case $C 7$

Figure 8. Concatenated voltage results of the entire LV grid when cases $C 5$ to $C 7$ are examined.

The total amount of injected energy by all DERs is presented in Figure 11. Case C1 injects all available power and no control is applied whatsoever. The total injected power by this case is $248 \mathrm{MWh}$, which will be used as a reference for the other cases. The reactive power voltage support and hard active power curtailment allow Case $C 2$ to inject a total of $218.3 \mathrm{MWh} / \mathrm{a}$. By using different colors, a segregation of the injected energy per DER is presented. In Case $C 2$, some of the single-phase connected DERs are curtailed and also $\mathrm{DER}_{24}$ and $\mathrm{DER}_{52}$. When the three-phase positive-sequence control strategy is used, $\mathrm{DER}_{24}$ droops slightly more energy compared to case $C 2$, while $\mathrm{DER}_{52}$ injects almost twice the energy compared with the same case. In addition, none of the single-phase DERs is subjected to hard curtailment. Overall, in case C3 total of $219.5 \mathrm{MWh} / \mathrm{a}$ are injected which is 1.2 MWh/a more compared to case $C 2$.

The negative-sequence voltage component mitigation is assigned to case $C 4$. The annual injected energy by this case is $220 \mathrm{MWh}$, which is slightly more compared to the previous cases. This control strategy considered an initial value of the $g_{d 2}=50 \mathrm{p}$.u. Although such a high value of the damping conductance is used, the injected energy is lower compared to the modified damping control strategy with initial value of $g_{d}=3 \mathrm{p} . \mathrm{u}$. (case C5). In this case, total of $224.7 \mathrm{MWh} / \mathrm{a}$ are injected, which is $2.7 \mathrm{MWh} / \mathrm{a}$ more compared to case $\mathrm{C} 4$.

Cases $C 6$ and $C 7$ represent the modified damping control strategy with initial values of the damping conductance 10 and 50 p.u., respectively. The difference between these cases in terms of annual energy exchange is very small-231.1 MWh and 231.3 MWh, respectively. Despite the fact that cases $C 4$ and $C 7$ use the same value of the damping conductance, impacting the zero-sequence component results in less energy drooping.

A common trend in all active power drooping control strategies is that with increasing the damping conductance, the injected energy by $\mathrm{DER}_{24}$ and $\mathrm{DER}_{52}$ gradually increases. Almost no energy 
is drooped by $\mathrm{DER}_{59}$ and $\mathrm{DER}_{70}$ because the penetration level of renewables in their feeders is very low and no power quality issues are observed.

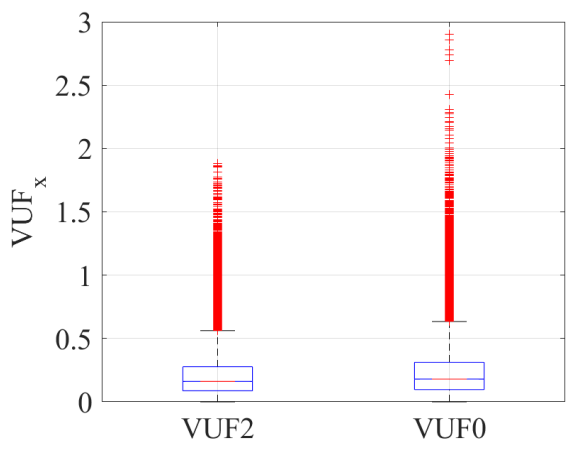

(a) Voltage unbalance factors of case $\mathrm{C1}$

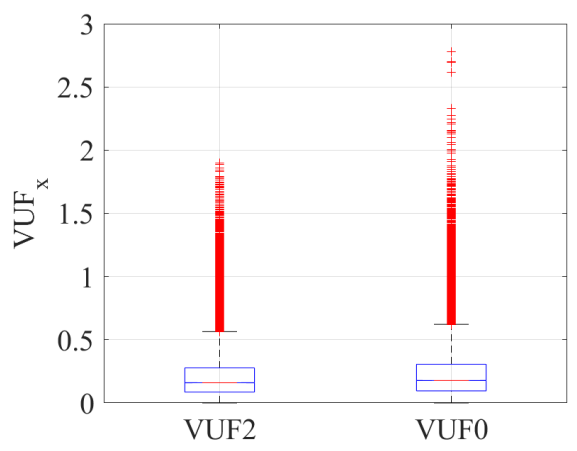

(c) Voltage unbalance factors of case $\mathrm{C3}$



(b) Voltage unbalance factors of case $C 2$

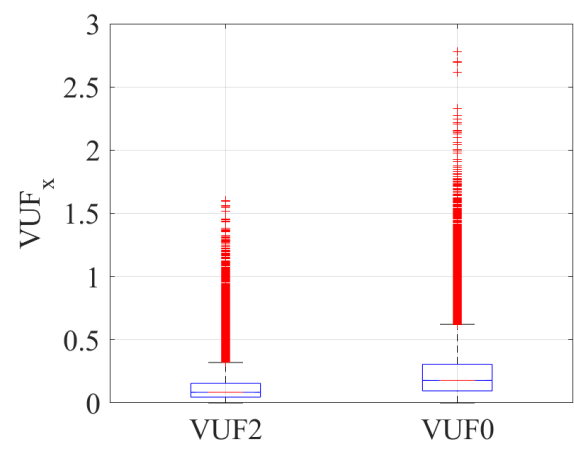

(d) Voltage unbalance factors of case $C 4$

Figure 9. Concatenated VUFsresults of the entire LV grid when cases $C 1$ to $C 4$ are examined.

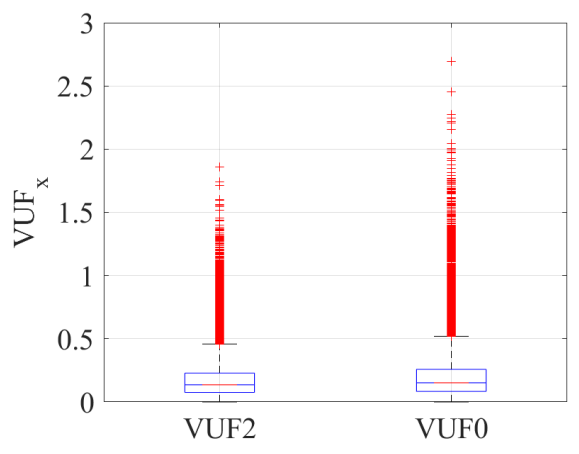

(a) Voltage unbalance factors of case $\mathrm{C5}$.

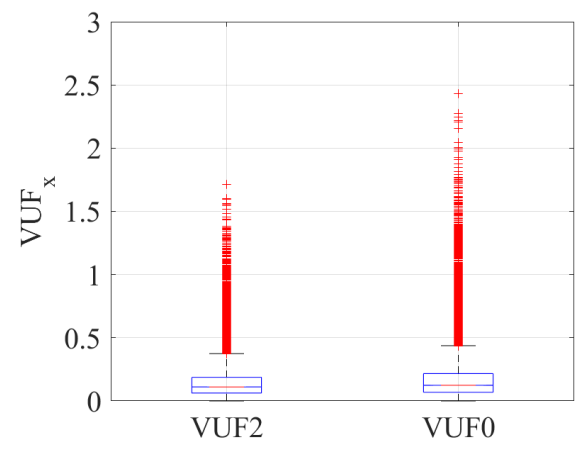

(b) Voltage unbalance factors of case $\mathrm{C} 6$

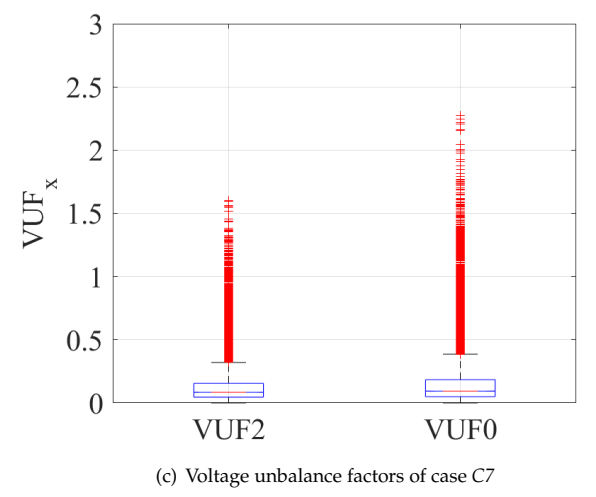

Figure 10. Concatenated VUFs results of the entire LV grid when cases $C 5$ to $C 7$ are examined. 


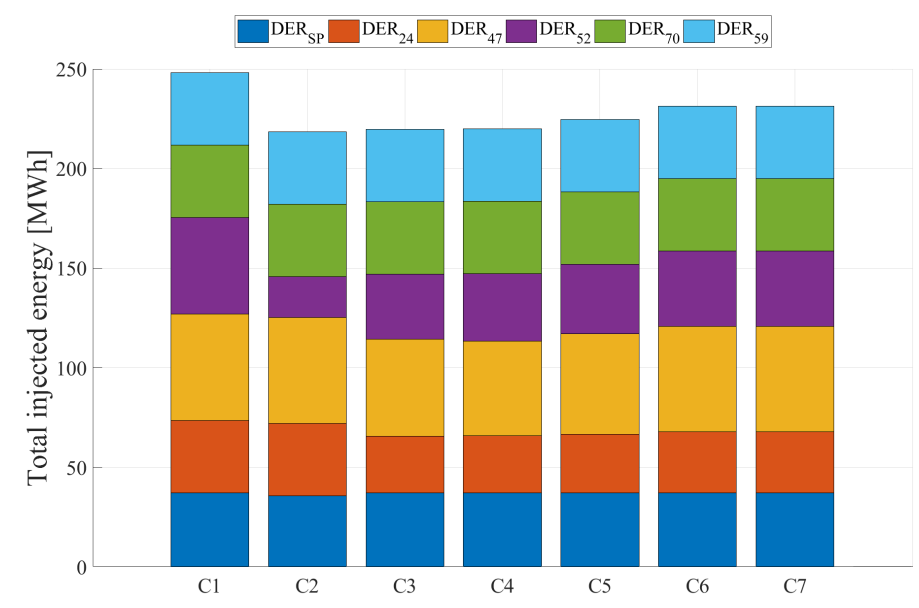

Figure 11. Total annual injected power by DERs when different control strategies are applied.

The aggregated energy losses in all feeders are presented in Figure 12. Case $C 0$ considers only loads and it leads to losses of $8.26 \mathrm{MWh} / \mathrm{a}$. When DER inject all available power $(\mathrm{C} 1)$ the losses are doubled and reach $16.52 \mathrm{MWh} / \mathrm{a}$. In case $\mathrm{C} 2$, some active power is curtailed which reduces the losses to $12.4 \mathrm{MWh} / \mathrm{a}$. The drooped positive-sequence control strategy does not inject any reactive power which leads to lower losses (10.57 MWh/a) compared to $C 2$.

In case $C 4$, the negative-sequence component mitigation leads to slightly more losses (10.7 MWh/a) compared to C3. Since both cases do not impact the zero-sequence component, the only reason for the loss increase is the higher energy injection of $1.2 \mathrm{MWh} /$ a compared to case $C 3$.

The modified three-phase damping control strategy with $g_{d}$ values of 3 p.u., 10 p.u. and 50 p.u. is represented by cases $C 5,6$ and $C 7$, respectively. These cases lead to losses of $9.83 \mathrm{MWh} / \mathrm{a}, 9.64 \mathrm{MWh} / \mathrm{a}$ and 9.59 MWh/a, respectively. This is a grid performance improvement between $2.57 \mathrm{MWh} / \mathrm{a}$ and $2.81 \mathrm{MWh} / \mathrm{a}$ compared to case $\mathrm{C} 3$.

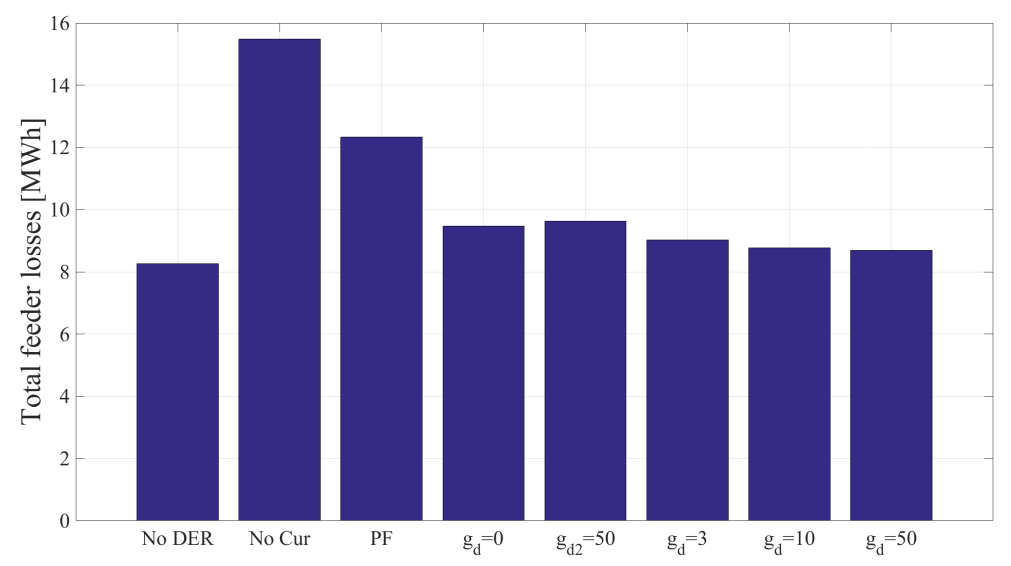

Figure 12. Total feeder losses when different control strategies are applied (No DER-C0, No Cur (No curtailment) - C1, PF (C2) - Variable power factor, $g_{d}=0$ (C3) - drooped positive-sequence control strategy, $g_{d 2}=50$ (C4) damping control strategy $\mathrm{VUF}_{2}$ only, $g_{d}=3, g_{d}=10$ and $g_{d}=50$ (C5-C7) drooped three-phase damping control strategy)

From the presented case studies it can be seen that even the drooped positive-sequence control strategy has a better performance compared to the hard active power curtailment with reactive 
power exchange. In summary, three-phase damping control strategy considered in case $C 7$ droops 16.6 MWh/a compared to the reference case $C 1$ while the currently employed control strategy with reactive power exchange, curtails about $30 \mathrm{MWh} / \mathrm{a}$.

Finally, a comparison between all test cases is listed in Table 2. The control strategies are rated from poor to excellent based on the results obtained in the presented simulations. They are also rated on four key performance indicators such as energy exchange, ability to control and maintain the grid voltage and voltage unbalance, as well as grid losses.

Table 2. Comparison table of the performance of the different control strategies.

\begin{tabular}{|c|c|c|c|c|c|}
\hline Case & Control Strategy & Energy & Voltage Control & Voltage Unbalance & Grid Losses \\
\hline $\mathrm{C1}$ & $\begin{array}{c}\text { No } \\
\text { Control }\end{array}$ & Excellent & Poor & Poor & Poor \\
\hline $\mathrm{C} 2$ & $\begin{array}{l}\text { Positive-sequence control } \\
\text { strategy with variable PF }\end{array}$ & Poor & Good & Poor & Poor \\
\hline C3 & $\begin{array}{l}\text { Drooped positive-sequence } \\
\text { control strategy } g_{d}=0\end{array}$ & Good & Excellent & Poor & Very good \\
\hline$C 4$ & $\begin{array}{l}\text { Drooped three-phase damping } \\
\text { control strategy with } g_{d 2}=50\end{array}$ & Very good & Excellent & Good & Good \\
\hline C5 & $\begin{array}{l}\text { Drooped three-phase damping } \\
\text { control strategy with } g_{d}=3\end{array}$ & Good & Excellent & Excellent & Very good \\
\hline C6 & $\begin{array}{l}\text { Drooped three-phase damping } \\
\text { control strategy with } g_{d}=10\end{array}$ & Very good & Excellent & Excellent & Very good \\
\hline$C 7$ & $\begin{array}{l}\text { Drooped three-phase damping } \\
\text { control strategy with } g_{d}=50\end{array}$ & Very good & Excellent & Excellent & Excellent \\
\hline
\end{tabular}

\subsection{Discussion for Possible Provision of Ancillary Services}

In the literature, it is often mentioned that overvoltages and voltage unbalance are the most common problems in LV grids with areas with high penetration of DERs. Up to this point, the modified three-phase damping control strategy showed superior performance in terms of voltage control, injected power and grid loss reduction, compared to the traditional reactive power voltage control, hard curtailment, and positive-sequence current injection. The presented simulations treat the power quality issues in a steady-state mode via time series simulations. Nevertheless, in $[39,40]$ the transient behavior of the three-phase damping control strategy is examined under variety of voltage dip types and residual voltages. In [40], a solution for a simultaneous voltage dip and harmonic mitigation are proposed. In [19], the integration of the battery energy storage systems into the three-phase damping control strategy is examined in terms of power quality and grid performance improvement. With this said, it can be concluded that the three-phase damping control strategy has a great potential to provide variety of ancillary services to the DSO. Moreover, further research can be performed into black start capabilities and frequency control so that services to the transmission system operator (TSO) can be provided.

The three-phase damping control strategy mitigates the voltage unbalance by acting resistively towards the zero- and negative-sequence voltage components. This behavior results in asymmetrical current injection depending on the rms value and angle of the respective phase voltage but it basically means that the DER will inject larger phase current in the phase with the lower voltage and smaller currents in the phases with the higher voltages. This intuitively means that some oversizing of the power electronic inverter is needed in order to accomplish voltage unbalance mitigation. In [12,19], very good results are achieved by oversizing the power electronic inverter with 25 to $30 \%$. Nowadays, the inverter costs are much lower compared to 10 or 15 years ago and such an oversizing will not impose a significant capital expenditure to the prosumers, who are interested in providing ancillary services.

It is worth mentioning that, in reality, the inverter efficiency will be lower than $100 \%$. This will result in lower energy injection of the presented test cases. It is also interesting to point out that unbalanced grid conditions are examined in the presented results. This implies that, the different 
legs of the three-phase voltage sourced inverter will operate at different points of the efficiency curve. Regardless of whether positive-sequence or three-phase damping control strategy is used, this effect will be present. This effect will be more prominent when the three-phase damping control strategy is used, because the exchanged currents will be highly asymmetrical, especially at high values of $g_{d}$. Nevertheless, the commercially available inverters have peak efficiency close to $98 \%$ and relatively flat efficiency curve with wide range, which will not deteriorate significantly the accuracy of the presented results.

\section{Conclusions}

From the conducted examination of different cases, it can be seen that the voltage support by means of reactive power is not an effective solution in LV grids with high penetration level of renewables. Besides the bigger amount of curtailed energy, the grid performance is also deteriorated due to the additional reactive power.

The mitigation of the negative-sequence voltage component alone, is not sufficient to increase the penetration level of DERs. The presented results showed too small improvement in energy exchange and grid performance compared to the case where both sequence components are impacted at the same value of the damping conductance $\left(g_{d}=50\right.$ p.u.). From the presented results it can be seen also that the overall LV grid losses are slightly deteriorated. In conclusion, in order to increase the penetration level of DERs and improve the grid performance the zero-sequence component must be mitigated. Excellent results are shown by the modified three-phase damping control strategy. Even low values of the damping conductance of 3 p.u. to 10 p.u. are sufficient to increase the annual energy injection, mitigate the voltage unbalance, prevent overvoltages and decrease the grid losses. The conducted simulation at high $g_{d}$ values showed that the three-phase damping control strategy is able to maintain the voltage levels even better; it maximizes the energy injection compared to the classical positive-sequence variable power factor control strategy with $13.4 \mathrm{MWh} / \mathrm{a}$ and reduces the grid losses with about $7 \mathrm{MWh} / \mathrm{a}$. Based on the presented simulation case studies, it can be concluded that the three-phase damping control strategy has a very good potential to provide ancillary services to the distribution system operator.

Author Contributions: D.V.B., M.J.M., and J.L. have written the text and perfomed the simulations. J.V.d.V. has provided valuable inside regarding the ancillary services in Fluvius. L.V. have provided reviews and editing of the proposed ideas and also supervision of the process. All authors have read and agreed to the published version of the manuscript.

Funding: The work of D. Bozalakov is conducted in the frame of project Interreg 2 Seas project-Ports Energy and Carbon Savings (PECS) (period 2014-2020). The project is co-funded by the European Regional Development Fund under subsidy contract No 2S01-020. Additional financing is also provided by the Dutch Provinces of North-Holland and South-Holland. The work of J. Laveyne in this paper is conducted in the frame of the ROLECS project (ICON HBC.2018.0527). This project is financed by Flanders Innovation and Entrepreneurship (VLAIO).

Acknowledgments: The authors would like to express their gratitude to Marjan Jerele, who is with a Slovenian DSO called Elektro Goreniska. He was very kind to provide all necessary data of the low voltage grid, which is used to perform the analyses in this article.

Conflicts of Interest: The authors declare no conflicts of interest.

\section{Abbreviations}

The following abbreviations and symbols are used in this manuscript.

$\begin{array}{llll}\text { APF } & \text { Active Power Factor } & v_{g} & \text { rms value of the grid voltage } \\ \text { BESS } & \text { Battery Energy Storage System } & v_{\mathrm{cpb}} & \text { constant power band voltage } \\ \text { CHP } & \text { Combined Heat and Power } & v_{g, \min } & \text { minimum grid voltage } \\ \text { DER } & \text { Distributed Energy Resources } & v_{g, \max } & \text { maximum grid voltage } \\ \text { DG } & \text { Distributed Generation unit } & p_{\mathrm{ac}} & \text { injected ac power } \\ \text { DSO } & \text { Distribution System Operator } & p_{\mathrm{dc}, \mathrm{nom}} & \text { nominal power of the primary source }\end{array}$




\begin{tabular}{|c|c|c|c|}
\hline DSTATCOM & Distributed STAtic COMpensator & $p_{\mathrm{dc}}^{\bullet}$ & delivered power by the primary source \\
\hline DVR & Dynamic Voltage Restorer & $p_{\mathrm{dc}}$ & input dc power \\
\hline FPF & Fixed Power Factor & $\Delta \mathrm{PF}$ & Power Factor deviation \\
\hline LV & Low Voltage & $\underline{v}_{x}$ & rms value of the respective voltage \\
\hline MV & Medium Voltage & $\theta_{x}$ & phase angle of the phase voltage \\
\hline OLTC & On-Load Tap Changer & $\underline{i}_{0}, \underline{i}_{1}, \underline{i}_{2}$ & zero-, positive- and negative-sequence currents \\
\hline PF & Power Factor & $\underline{v}_{0}, \underline{v}_{1}, \underline{v}_{2}$ & zero-, positive- and negative-sequence voltages \\
\hline PLL & Phase Locked Loop & $g_{1}$ & fundamental input conductance \\
\hline PV & Photo Voltaic & $\underline{i}_{a}, \underline{i}_{b}, \underline{v}_{c}$ & vectors of the phase currents \\
\hline TSO & Transmission System Operator & $\underline{v}_{a}, \underline{v}_{b}, \underline{v}_{c}$ & vectors of the phase voltages \\
\hline VSI & Voltage Sourced Inverter & $G_{d}$ & absolute value of the damping conductance \\
\hline VUF & Voltage Unbalance Factor & $g_{d}$ & per unit value of the damping conductance \\
\hline \multirow[t]{5}{*}{ UPFC } & Unified Power Factor Corector & $V_{\text {nom }}$ & absolute nominal value of the grid voltage \\
\hline & & $g_{d 2}$ & negative-seqeunce damping conductance \\
\hline & & $P_{\mathrm{dc}, \text { nom }}$ & absolute nominal dc power \\
\hline & & $V_{\text {base }}$ & absolute base value of the grid voltage \\
\hline & & $P_{\mathrm{dc}, \text { base }}$ & base power of the VSI \\
\hline
\end{tabular}

Only in Equations (8), (12), and (17)

$v_{x}$ and $v_{y}-x \in[a, b, c], y \in[a, b, c]$ but $x \neq y$

$\theta_{\mathrm{x}}$ and $\theta_{\mathrm{y}}-x \in[a, b, c], y \in[a, b, c]$ but $x \neq y$

\section{References}

1. Zsiborács, H.; Hegedüsné Baranyai, N.; Vincze, A.; Háber, I.; Pintér, G. Economic and Technical Aspects of Flexible Storage Photovoltaic Systems in Europe. Energies 2018, 11, 1445.

2. Weckx, S.; Driesen, J. Load Balancing With EV Chargers and PV Inverters in Unbalanced Distribution Grids. IEEE Trans. Sustain. Energy 2015, 6, 635-643.

3. Tolabi, H.B.; Ali, M.H.; Rizwan, M. Simultaneous Reconfiguration, Optimal Placement of DSTATCOM, and Photovoltaic Array in a Distribution System Based on Fuzzy-ACO Approach. IEEE Trans. Sustain. Energy 2015, 6, 210-218.

4. Behrouzian, E.; Bongiorno, M.; Teodorescu, R. Impact of Switching Harmonics on Capacitor Cells Balancing in Phase-Shifted PWM-Based Cascaded H-Bridge STATCOM. IEEE Trans. Power Electron. 2017, 32, 815-824, [CrossRef]

5. Idlbi, B.; von Appen, J.; Kneiske, T.; Braun, M. Cost-Benefit Analysis of Battery Storage System for Voltage Compliance in Distribution Grids with High Distributed Generation. Energy Procedia 2016, 99, 215-228.

6. Oureilidis, K.; Malamaki, K.N.; Gallos, K.; Tsitsimelis, A.; Dikaiakos, C.; Gkavanoudis, S.; Cvetkovic, M.; Mauricio, J.M.; Maza Ortega, J.M.; Ramos, J.L.M.; et al. Ancillary Services Market Design in Distribution Networks: Review and Identification of Barriers. Energies 2020, 13, 917.

7. Perez, R.; Rábago, K.R.; Trahan, M.; Rawlings, L.; Norris, B.; Hoff, T.; Putnam, M.; Perez, M. Achieving very high PV penetration-The need for an effective electricity remuneration framework and a central role for grid operators. Energy Policy 2016, 96, 27-35.

8. Milligan, M. Sources of grid reliability services. Electr. J. 2018, 31, 1-7.

9. Chaudhary, P.; Rizwan, M. Voltage regulation mitigation techniques in distribution system with high PV penetration: A review. Renew. Sustain. Energy Rev. 2018, 82, 3279-3287.

10. Sousa, J.L.; Brito, C.J.; Pires, V.F. Impact of photovoltaic systems with ancillary services in low voltage grids. In Proceedings of the 2016 15th Biennial Baltic Electronics Conference (BEC), Tallinn, Estonia, 3-5 October 2016; pp. 183-186.

11. Oyegoke, S.; Habtay, Y.; Maniatopoulos, M.; Kotsampopoulos, P.; Keates, S. Power Hardware In the Loop and Ancillary Service for Voltage Regulation in Low Voltage Grid. In Proceedings of the 2019 54th International Universities Power Engineering Conference (UPEC), Bucharest, Romania, 3-6 September, 2019; pp. 1-6.

12. Bozalakov, D.; Laveyne, J.; Desmet, J.; Vandevelde, L. Overvoltage and voltage unbalance mitigation in areas with high penetration of renewable energy resources by using the modified three-phase damping control strategy. Electr. Power Syst. Res. 2019, 168, 283-294. 
13. Yang, Y.; Li, H.; Aichhorn, A.; Zheng, J.; Greenleaf, M. Sizing Strategy of Distributed Battery Storage System with High Penetration of Photovoltaic for Voltage Regulation and Peak Load Shaving. IEEE Trans. Smart Grid 2014, 5, 982-991.

14. Hilton, G.; Cruden, A.; Kent, J. Comparative analysis of domestic and feeder connected batteries for low voltage networks with high photovoltaic penetration. J. Energy Storage 2017, 13, 334-343.

15. Chua, K.H.; Lim, Y.S.; Taylor, P.; Morris, S.; Wong, J. Energy Storage System for Mitigating Voltage Unbalance on Low-Voltage Networks With Photovoltaic Systems. IEEE Trans. Power Deliv. 2012, 27, 1783-1790.

16. Faessler, B.; Schuler, M.; Preißinger, M.; Kepplinger, P. Battery Storage Systems as Grid-Balancing Measure in Low-Voltage Distribution Grids with Distributed Generation. Energies 2017, 10, 2161.

17. Hesse, H.C.; Martins, R.; Musilek, P.; Naumann, M.; Truong, C.N.; Jossen, A. Economic Optimization of Component Sizing for Residential Battery Storage Systems. Energies 2017, 10, 835.

18. Behravesh, V.; Keypour, R.; Akbari Foroud, A. Control strategy for improving voltage quality in residential power distribution network consisting of roof-top photovoltaic-wind hybrid systems, battery storage and electric vehicles. Sol. Energy 2019, 182, 80-95.

19. Bozalakov, D.; Mnati, M.J.; Laveyne, J.; Desmet, J.; Vandevelde, L. Battery Storage Integration in Voltage Unbalance and Overvoltage Mitigation Control Strategies and Its Impact on the Power Quality. Energies 2019, 12, 1501.

20. Alam, M.J.E.; Muttaqi, K.M.; Sutanto, D. Community Energy Storage for Neutral Voltage Rise Mitigation in Four-Wire Multigrounded LV Feeders With Unbalanced Solar PV Allocation. IEEE Trans. Smart Grid 2015, 6, 2845-2855. [CrossRef]

21. Geth, F.; Tant, J.; Belmans, R.; Driesen, J. Balanced and unbalanced inverter strategies in battery storage systems for low-voltage grid support. IET Gener. Transm. Distrib. 2015, 9, 929-936. [CrossRef]

22. Nguyen, S.; Peng, W.; Sokolowski, P.; Alahakoon, D.; Yu, X. Optimizing rooftop photovoltaic distributed generation with battery storage for peer-to-peer energy trading. Appl. Energy 2018, 228, 2567-2580.

23. Zeh, A.; Witzmann, R. Operational Strategies for Battery Storage Systems in Low-voltage Distribution Grids to Limit the Feed-in Power of Roof-mounted Solar Power Systems. Energy Procedia 2014, 46, 114-123. [CrossRef]

24. Zangs, M.J.; Adams, P.B.E.; Yunusov, T.; Holderbaum, W.; Potter, B.A. Distributed Energy Storage Control for Dynamic Load Impact Mitigation. Energies 2016, 9, 647. [CrossRef]

25. Shaw-Williams, D.; Susilawati, C.; Walker, G. Value of Residential Investment in Photovoltaics and Batteries in Networks: A Techno-Economic Analysis. Energies 2018, 11, 1022. [CrossRef]

26. Bozalakov, D.V.; Vandoorn, T.L.; Meersman, B.; Papagiannis, G.K.; Chrysochos, A.I.; Vandevelde, L. Damping-Based Droop Control Strategy Allowing an Increased Penetration of Renewable Energy Resources in Low-Voltage Grids. IEEE Trans. Power Deliv. 2016, 31, 1447-1455. [CrossRef]

27. Vandevelde, L.; Meersman, B. Increasing the Penetration of the Renewable Energy Sources in the Distribution Grid by Developing Control Strategies and Using Ancillary Services (INCREASE); EC-FP7 Project. Grant Agreement No. 608998, Set. 2013; European Commission: Brussels, Belgium, 2016.

28. Kontis, E.O.; Kryonidis, G.C.; Chrysochos, A.I.; Demoulias, C.S.; Papagiannis, G.K. Long-term evaluation of DRES penetration in LV networks using droop control techniques. In Proceedings of the 2016 IEEE PES Innovative Smart Grid Technologies Conference Europe (ISGT-Europe), Ljubljana, Slovenia, 9-12 October 2016.

29. Vandoorn, T.L.; Kooning, J.D.; Meersman, B.; Vandevelde, L. Voltage-Based Droop Control of Renewables to Avoid On-Off Oscillations Caused by Overvoltages. IEEE Trans. Power Deliv. 2013, 28, 845-854. [CrossRef]

30. EN 50160:2010. Voltage Characteristics of Electricity Supplied by Public Distribution Networks; European copper institute, European Copper Institute: Brussels, Belgium, 2017.

31. Photovoltaics, D.G.; Storage, E. IEEE Standard Conformance Test Procedures for Equipment Interconnecting Distributed Resources with Electric Power Systems Amendment. Biochemistry 2005, 2015, 1-62.

32. Blaabjerg, F.; Teodorescu, R.; Liserre, M.; Timbus, A.V. Overview of Control and Grid Synchronization for Distributed Power Generation Systems. IEEE Trans. Ind. Electron. 2006, 53, 1398-1409. [CrossRef]

33. Bozalakov, D.V.; Mnati, M.J.; Laveyne, J.; den Bossche, A.V.; Vandevelde, L. Voltage Unbalance and Overvoltage Mitigation by Using the Three-phase Damping Control Strategy in Battery Storage Applications. In Proceedings of the 7th International Conference on Renewable Energy Research and Applications (ICRERA), Paris, France, 14-17 October 2018; pp. 753-759. 
34. Bozalakov, D.; Meersman, B.; Bottenberg, A.; Rens, J.; Desmet, J.; Vandevelde, L. Dc-bus voltage balancing controllers for split dc-link four-wire inverters and their impact on the quality of the injected currents. CIRED Open Access Proc. J. 2017, 564-568. [CrossRef]

35. Vandoorn, T.L.; Meersman, B.; Degroote, L.; Renders, B.; Vandevelde, L. A Control Strategy for Islanded Microgrids with DC-Link Voltage Control. IEEE Trans. Power Deliv. 2011, 26, 703-713. [CrossRef]

36. Labeeuw, W.; Deconinck, G. Residential Electrical Load Model Based on Mixture Model Clustering and Markov Models. IEEE Trans. Ind. Inform. 2013, 9, 1561-1569, [CrossRef]

37. Laveyne, J.; Bozalakov, D.; Van Eetvelde, G.; Vandevelde, L. Impact of solar panel orientation on the integration of solar energy in low-voltage distribution grids. Int. J. Photoenergy 2020, 2020, 13. [CrossRef]

38. Kryonidis, G.C.; Kontis, E.O.; Chrysochos, A.I.; Demoulias, C.S.; Bozalakov, D.; Meersman, B.; Vandoorn, T.L.; Vandevelde, L. A simulation tool for extended distribution grids with controlled distributed generation. In Proceedings of the 2015 IEEE Eindhoven PowerTech, Eindhoven, The Netherlands, 29 June-2 July, 2015.

39. Bozalakov, D.; Vandoorn, T.; Meersman, B.; Demoulias, C.; Vandevelde, L. Voltage dip mitigation capabilities of three-phase damping control strategy. Electr. Power Syst. Res. 2015, 121, 192-199. [CrossRef]

40. Bozalakov, D. Control Strategies for Grid-Connected Inverters Enabling Power Quality Improvement and Increased Penetration of Renewable Energy Resources in the Low Voltage Distribution Networks. Ph.D. Thesis, Gent University, Faculty of Engineering and Architecture, Ghent, Belgium, 2019.

Publisher's Note: MDPI stays neutral with regard to jurisdictional claims in published maps and institutional affiliations.

(C) 2020 by the authors. Licensee MDPI, Basel, Switzerland. This article is an open access article distributed under the terms and conditions of the Creative Commons Attribution (CC BY) license (http://creativecommons.org/licenses/by/4.0/). 